\title{
Disentangling the genetic bases of Saccharomyces cerevisiae nitrogen consumption and adaptation to low nitrogen environments in wine fermentation
}

\author{
Eduardo I. Kessi-Pérez ${ }^{1,2}$ ([) Jennifer Molinet ${ }^{1,2}$ (]) and Claudio Martínez ${ }^{1,2^{*}}$ (])
}

\begin{abstract}
The budding yeast Saccharomyces cerevisiae has been considered for more than 20 years as a premier model organism for biological sciences, also being the main microorganism used in wide industrial applications, like alcoholic fermentation in the winemaking process. Grape juice is a challenging environment for $\mathrm{S}$. cerevisiae, with nitrogen deficiencies impairing fermentation rate and yeast biomass production, causing stuck or sluggish fermentations, thus generating sizeable economic losses for wine industry. In the present review, we summarize some recent efforts in the search of causative genes that account for yeast adaptation to low nitrogen environments, specially focused in wine fermentation conditions. We start presenting a brief perspective of yeast nitrogen utilization under wine fermentative conditions, highlighting yeast preference for some nitrogen sources above others. Then, we give an outlook of S. cerevisiae genetic diversity studies, paying special attention to efforts in genome sequencing for population structure determination and presenting QTL mapping as a powerful tool for phenotype-genotype correlations. Finally, we do a recapitulation of $S$. cerevisiae natural diversity related to low nitrogen adaptation, specially showing how different studies have left in evidence the central role of the TORC1 signalling pathway in nitrogen utilization and positioned wild S. cerevisiae strains as a reservoir of beneficial alleles with potential industrial applications (e.g. improvement of industrial yeasts for wine production). More studies focused in disentangling the genetic bases of S. cerevisiae adaptation in wine fermentation will be key to determine the domestication effects over low nitrogen adaptation, as well as to definitely proof that wild S. cerevisiae strains have potential genetic determinants for better adaptation to low nitrogen conditions.
\end{abstract}

Keywords: Saccharomyces cerevisiae, Wine yeasts, Nitrogen consumption, Wine fermentation, Natural variation, Wild alleles, QTL mapping, GWAS, ASE, TORC1 pathway

\section{Background}

The budding yeast Saccharomyces cerevisiae (hereinafter, called "S. cerevisiae" or simply "yeast") has been considered for more than 20 years as one of the main model

*Correspondence: claudio.martinez@usach.cl

1 Departamento de Ciencia y Tecnología de los Alimentos, Universidad de Santiago de Chile (USACH), Santiago, Chile

Full list of author information is available at the end of the article organisms for biological sciences such as genetics and molecular biology, being the first eukaryotic organism with its genome fully sequenced in 1996, milestone that required a combined international effort [1]. Nowadays, yeast continues being a workhorse to assess different biological questions, such as the minimal genome needed for cell functionality and, probably, it will be soon the first synthetic eukaryotic genome $[2,3]$.

c) The Author(s) 2020. This article is licensed under a Creative Commons Attribution 4.0 International License, which permits use, sharing, adaptation, distribution and reproduction in any medium or format, as long as you give appropriate credit to the original author(s) and the source, provide a link to the Creative Commons licence, and indicate if changes were made. The images or other third party material in this article are included in the article's Creative Commons licence, unless indicated otherwise in a credit line to the material. If material is not included in the article's Creative Commons licence and your intended use is not permitted by statutory regulation or exceeds the permitted use, you will need to obtain permission directly from the copyright holder. To view a copy of this licence, visit http://creativeco mmons.org/licenses/by/4.0/. The Creative Commons Public Domain Dedication waiver (http://creativecommons.org/publicdomain/ zero/1.0/) applies to the data made available in this article, unless otherwise stated in a credit line to the data. 
Beyond of its extraordinary facility for genetic manipulation and the wide repertory of molecular biology techniques for genome edition, S. cerevisiae is also the main microorganism industrially utilized worldwide and a biological platform for biotechnology, with applications that included production of wine, beer, bread, heterologous proteins, vaccines and high value metabolites [4-8]. Altogether, the uses of yeast as model organism and its multiple biotechnological applications have boosted the genome sequencing of a great number of strains, revelling the genomics features that permit its adaptation to diverse ecological niches, including industrial ones, as is the case with wine fermentation $[9,10]$.

Saccharomyces cerevisiae is the main microorganism responsible for the alcoholic fermentation in the winemaking process, contributing not only with the alcoholic degree but also with flavours and aromas to the final product $[11,12]$. In this context, this species has different adaptations to the fermentative environments; a very interesting recent review discusses the mechanisms of yeast adaptation to wine fermentation from an "omics" point of view [13]. For example, S. cerevisiae is a Crabtree positive yeast, i.e. in the presence of a fermentable carbon source (like glucose or fructose), its metabolism proceeds mainly via fermentation rather than respiration, even in the presence of oxygen [14]. This Crabtree positive condition is ecologically important for $S$. cerevisiae because wine fermentation is a complex microbiological process, where the rapid transformation of sugars (glucose and fructose) into ethanol allows it to outcompete other present microorganisms [15] (for new perspectives in the subject, see $[16,17])$.

Furthermore, the grape juice itself is a challenging environment for yeasts, where is necessary face up to temperature fluctuations, low $\mathrm{O}_{2}$, low $\mathrm{pH}$ (between 2 and 3 ), high osmotic pressure ( $20 \%$ of sugar concentration), high sulphite levels, ethanol toxicity and nutritional deficiencies $[13,18,19]$. For example, at the beginning of wine fermentation a strong osmotic stress is induced by high sugar concentrations, potentially causing a reduction of both growth and viability, which is sensed by yeast cells through multiple signalling pathways that allow them to quickly respond to altered osmolarity [20]. In contrast to sugar, S. cerevisiae has to adapt to the depletion of essential nutrients during first stages of fermentation; in this context, nitrogen is the main limiting nutrient during wine fermentation, being highly correlated with fermentation kinetics $[8,21]$.

Nitrogen deficiencies in grape juice impairs the fermentation rate and yeast biomass production, which causes stuck or sluggish fermentations [21], which is recognized as one of the main problems in wine industry, generating sizeable economic losses [22]. In addition, nitrogen deficiencies mainly affect the highest quality red wines, due to the complex composition of the grape must utilized in its production, which contains tannins and phenols that induce the stress response in yeast $[23,24]$. In this context, winemakers try to solve this problem by two main strategies: (i) vineyard management through the use of nitrogen fertilizers and (ii) nitrogen supplementation of the grape must [25]. This suggests that industrial wine yeasts are not well adapted to low nitrogen environments, requiring high levels of nitrogen to complete the fermentation process [26].

In the present review, we summarize some recent efforts in the search of causative genes that account for yeast adaptation to low nitrogen environments, specially focused in wine fermentation conditions. To achieve this, we start by presenting a brief perspective of yeast nitrogen utilization under wine fermentative conditions, then an outlook of yeast genetic diversity studies, and finally a recapitulation of yeast natural diversity related to low nitrogen adaptation, with special emphasis in the central role of the TORC1 signalling pathway in nitrogen utilization and the idea that wild $S$. cerevisiae strains are a reservoir of beneficial alleles with potential industrial applications (due to its impact in processes related to nitrogen sensing and uptake).

\section{Main text}

\section{Yeast nitrogen utilization under wine fermentative conditions}

Several reviews exist that focus on yeast nitrogen sensing, signalling, transport, assimilation and metabolism [27-35]. A general conclusion is that yeast growth rate is not only associated with the amount of available nitrogen, but also with the quality of the nitrogen source [18, 27]. Thus, nitrogen sources sustaining high growth rate such as glutamine, glutamate, asparagine and ammonium are considered as preferred, whereas proline, allantoin and urea allows slow growth rate and, therefore, are considered as non-preferred nitrogen sources [28].

Nitrogen can be found in various forms in grape must, with yeast consuming mainly ammonium and amino acids; from them, the main amino acids present are proline, arginine, alanine, glutamate, glutamine, serine and threonine, in addition to ammonia [36]. Moreover, in wine fermentation context these nitrogen sources are consumed following a specific order, where asparagine, threonine, glutamine, leucine, histidine, methionine, isoleucine, serine, glycine and phenylalanine are utilized at the beginning of the fermentation, while ammonium, valine, arginine, alanine, tryptophan and tyrosine are preferred at later times [37]. This preference for different nitrogen sources is the aftermath of a tight metabolic regulation system where four different mechanisms regulate 
nitrogen utilization: Ssy1-Ptr3-Ssy5 system (SPS), nitrogen catabolic repression (NCR), retrograde signalling pathway (RTG) and the general control of amino acids (GAAC); with all of them in turn regulated by the TORC1 signalling pathway $[29,30]$.

Under nitrogen limited conditions, yeast cells grow slowly, reducing the ribosome biogenesis, protein translation and arresting the cell cycle in G1 [38]. There are a couple of excellent reviews covering this topic in wine fermentation context $[18,21,26]$, mainly focused on studies that used media containing a mixture of different nitrogen sources mimicking natural grape musts. Remarkably, several groups around the world have shown that the nitrogen requirements of $S$. cerevisiae are strain-dependent, i.e. different yeast strains have different necessities of nitrogen, and then have different capacities to growth and perform wine fermentation in nitrogen-limited musts [39-43]. In this context, the wide phenotypic diversity observed in S. cerevisiae for nitrogen requirements is probably a consequence of its genetic diversity, being an important challenge to disentangle this diversity.

\section{Yeast genetic diversity Genome sequencing and population structure}

As abovementioned, S. cerevisiae is a model organism with its genome fully sequenced since 1996 [1]. Since then, different attempts have been made to unveil the genetic diversity and population structure of the species. The first attempts to unveil the genetic diversity present in $S$. cerevisiae were done sequencing individual genes and using molecular markers, which showed the presence of two main yeast populations: domesticated yeasts associated with human activities (wine, beer, bread, etc.) and wild yeasts from natural environments without human intervention [44-46].

These two populations reflect different evolutionary trajectories, for instance, wine yeasts have been selected by centuries of human activity, preferring traits such as ethanol production and fruity flavours and fragrances; while wild yeasts have faced challenging environments with scarcity of carbon and nitrogen sources [47]. Furthermore, this divergent track of selection was confirmed by assaying the ability of wild yeasts to growth in a wide range of carbon and nitrogen sources, which contrasts with the limited nitrogen and carbon sources sustaining growth in wine yeasts [48].

After these first attempts, the population structure of $S$. cerevisiae was finally resolved by genome sequencing of 37 yeast strains isolated from different ecological niches, demonstrating the presence of five clean lineages or subpopulations in the species: Malaysian (MA), Sake (SA), North American (NA), West African (WA) and Wine/
European (WE) $[49,50]$. Afterward, the genome sequencing of 100 yeast strains confirmed the presence of these five clean lineages (MA, NA, SA, WA and WE) in the population structure of $S$. cerevisiae [51]. Interestingly, the information obtained by these and other sequencing efforts has revealed unique sets of genetic features related with yeast strains specific niche adaptation, often absent in the reference genome, some of them acquired by horizontal gene transfer events from distant species or by introgression from closely relative ones [52-58].

Recently, the "1002 yeast genomes project" has been finished, representing the most complete catalogue of the genetic variation in S. cerevisiae, where a population of 1011 yeast strains isolated from different ecological niches has been sequenced [59]. In the "1011 population", a total of 26 clades were described, expanding the number of phylogenetic clusters initially observed in the species; of them, 362 isolates were grouped into the WE cluster [59]. Additionally, the sequencing of this huge population confirmed that isolates from Asia have the greatest genetic diversity within the species $[59,60]$. Nowadays, the repertory of yeast strains with sequenced genomes includes wild isolates from environments such as tree bark and flowers, and domesticated isolates from clinical, dairy, cheese, brewery and vineyard environments (among others) [49, 51, 54, 59-62]; with the "1011 yeasts population" including most the genetic variation existing in S. cerevisiae and becoming a powerful resource for genotype-phenotype correlations [59].

\section{Phenotype-genotype correlation by QTL mapping}

The extensive knowledge and information generated by the sequencing projects in S. cerevisiae has been accompanied by massive phenotyping efforts under different culture conditions, showing that phenotypic variation is wider than genotypic diversity in the species $[63,64]$. This observation suggests that yeast has a broad phenotypic plasticity and, more importantly, that multiple genes contributes to most of the phenotypes studied, which are commonly refers as polygenic traits or complex traits [65].

QTL mapping has been the main experimental approximation to fill the gap between genotype and phenotype in yeast [66]. In this approach, a population of individuals derived from a cross is genotyped and phenotyped, allowing the statistical correlation between genotype and phenotype to map genes affecting the trait of interest [67, 68]. This approach has been extensively used in yeast for mapping causatives genes affecting phenotypes such as thermotolerance [69-71], chemical resistance [69, 72], translation termination [73] and dehydration stress tolerance [74], among many others, being particularly important in identifying quantitative trait nucleotides 
impacting technological performances of industrial yeast strains (see [75] for more details in the topic).

In this context, several QTLs have been mapped for phenotypes associated with the fermentation process, such as ethanol production, residual sugar and acidity [76-80], as well as QTLs involved in nitrogen-limited fermentations and in nitrogen consumption and utilization [41, 42, 78, 81-85] (Table 1). Overall, QTL mapping has proved to be an efficient tool for the detection of genes responsible of the phenotypic variation observed in populations generated by crosses, particularly for fermentative phenotypes.

\section{Yeast natural diversity related to low nitrogen adaptation Nitrogen consumption}

Several genes have been linked with yeast strains differences in nitrogen consumption, under laboratory and/or fermentative conditions, not only by QTL mapping but also using other experimental strategies (Table 1). For example, transcriptomic studies have given insights into groups of genes related to nitrogen uptake [86], nitrogen requirements [39] and response to nitrogen availability $[87,88]$, all of them using wine strains. In other approach, a massive hemizygote analysis showed that the inability of a commercial wine strain to utilize methionine is a consequence of mutations in ADE5,7, ARO8 and VBA3 genes [40]. In a similar way, the use of a wine yeast deletion collection (WYDC) showed that deletion of MFA2 resulted in a decrease in fermentation duration in nitrogen-limited conditions [89].
In a different genetic strategy, allele specific expression (ASE), an approach that allows the study of eQTLs (expression QTLs) through the combination of recombinant populations (as in traditional QTL mapping) and sequencing-based methods (RNA-seq), has also been used in studies that showed that coding and non-coding mutations in ASN1 explains nitrogen consumption differences between different yeast strains [90] and that polymorphisms within the coding region of GDB1 underlie fermentation kinetics differences [91].

Anyway, QTL mapping has been a preferred method for detection of genes linked to industrial-importance phenotypes in general (reviewed in [75]) and nitrogen consumption in particular (Table 1). One strategy has been the use of recombinant populations derived from wine strains. For example, using a recombinant population derived from two wine strains and phenotyped for nitrogen requirements for efficient fermentation, $A R G 8$, $B I O 3, G C N 1$ and $M D S 3$ genes were linked to key roles in nitrogen metabolism and signalling [82]. Other study found, utilizing a recombinant population derived from a wine and a laboratory strain, that $A B Z 1$ gene controls the fermentation rate through modulation of nitrogen utilization [76].

In contrast, another useful strategy is to use strains representative of the clean lineages abovementioned for S. cerevisiae [49] as the parental strains of the recombinant populations. Through this approach, several genes have been mapped and validated: AGP1, ASI1 and GLT1 for variation in nitrogen sources consumption underlying differences in the central nitrogen metabolism [41];

Table 1 Examples of nitrogen-associated genes identified by QTL mapping and other approaches

\begin{tabular}{|c|c|c|c|c|c|c|c|c|}
\hline \multicolumn{3}{|c|}{ Phenotype under study } & \multicolumn{3}{|c|}{ Experimental condition } & \multirow[t]{2}{*}{ Method(s) of detection } & \multirow[t]{2}{*}{ Gene(s) identified } & \multirow[t]{2}{*}{ Reference(s) } \\
\hline A & B & $C$ & D & $\mathbf{E}$ & $\mathbf{F}$ & & & \\
\hline & $x$ & $x$ & $x$ & & $x$ & QTL mapping (ISA) plus microarray & $A B Z 1$ & {$[76]$} \\
\hline \multirow[t]{3}{*}{$x$} & & & $x$ & $x$ & $x$ & $\mathrm{MHA}$ & $A D E 5,7, A R O 8, V B A 3$ & {$[40]$} \\
\hline & & $x$ & $x$ & & $x$ & QTL mapping (BSA) & ARG8, BIO3, GCN1, MDS3 & {$[82]$} \\
\hline & $x$ & & $x$ & & $x$ & QTL mapping (ISA) & $A G P 1, A S / 1, G L T 1$ & {$[41]$} \\
\hline \multirow[t]{7}{*}{$x$} & & & & $x$ & & QTL mapping (ISA) & DAL1, DAL4, RIM15, PUT4 & {$[48]$} \\
\hline & $x$ & $x$ & $x$ & $x$ & $x$ & QTL mapping (ISA) & RIM15 & {$[42]$} \\
\hline & $x$ & & $x$ & & $x$ & $\begin{array}{l}\text { ASE } \\
\text { plus ASB }\end{array}$ & ASN1 & {$[90]$} \\
\hline & & $x$ & $x$ & & $x$ & ASE & GDB1 & {$[91]$} \\
\hline & $x$ & & $x$ & & $x$ & QTL mapping (ISA) plus BSR-seq & $\begin{array}{l}\text { ARO1, ALP1, ASI2, CPS1, EAP1, } \\
\text { GTR1, LYP1, NPR1, PDC1, RPI1, } \\
\text { SAP185, SCH9, SIT4, TOR2 }\end{array}$ & {$[81,83,85]$} \\
\hline & & $x$ & & $x$ & $x$ & WYDC & $\begin{array}{l}\text { AAT2, BRO1, EAR1, MFA2, MMS2, } \\
\text { MRP17, MVB12, TPK2, UBC13, } \\
\text { UB14, UBP7 }\end{array}$ & {$[89]$} \\
\hline & & $x$ & $x$ & $x$ & $x$ & QTL mapping (ISA) & $K A E 1$ & {$[84]$} \\
\hline
\end{tabular}

A: Growth kinetics. B: nitrogen sources consumption. C: fermentation kinetics. D: nitrogen-sufficient condition. E: nitrogen-limited condition. F: wine condition 
DAL1, DAL4, RIM15 and PUT4 for nitrogen source use variations [48]; and RIM15, this last gene having an antagonistic pleiotropy, with a wine strain allele conferring a greater nitrogen utilization efficiency and glycerol production but also fungicide sensitivity [42].

An alternative to the use of these bi-parental recombinant populations is the utilization of the SGRP-4X population, a multi-parental recombinant population derived from four representative strains from lineages NA, SA, WA and WE [92]. Using this population and a combined strategy of QTL mapping and BSR-seq (bulk segregant RNA-seq), allelic variants in a large set of genes (ARO1, ALP1, ASI2, CPS1, EAP1, GTR1, LYP1, NPR1, PDC1, RPI1, SAP185, SCH9, SIT4 and TOR2) were identified as responsible for nitrogen consumption differences during wine fermentation $[81,83,85]$. Interestingly, half of these genes (EAP1, GTR1, NPR1, SAP185, SCH9, SIT4 and TOR2) are directly linked to the TORC1 signalling pathway in yeast [85].

\section{TORC1 pathway-associated genes}

TORC1 signalling pathway is a pleiotropic signalling pathway, conserved through the eukaryotic domain from yeast to humans (where is known as "mTORC1"), that connects nutrient availability with growth, playing a central role in general metabolism regulation, specially linked to nitrogen metabolism [26]. In nitrogen starvation conditions, TORC1 activates autophagy, stress response genes, nitrogen catabolic genes and ammonium permeases; on the contrary, it represses protein biosynthesis, amino acid biosynthesis, translation initiation and ribosome biogenesis [28].

One of the major actual challenges in the TORC1 field is to determine exactly how intracellular levels of nitrogen are sensed by the TORC1 complex and how this pathway differentiate between preferred and non-preferred nitrogen sources $[29,30,93,94]$. In this sense, a recently developed method allows the indirect monitoring of TORC1 activation for hundreds of strains, enabling the study of this phenotype by approaches like QTL mapping [95]. Using these experimental capacities, KAE1 allelic variants were identified to affect both TORC1 activation by glutamine and fermentation kinetics under nitrogen-sufficient and nitrogen-limited wine conditions [84] (Fig. 1).

We can add to this last antecedent the fact that that allelic variants of EAP1, GTR1, NPR1, SAP185, SCH9, SIT4 and TOR2, all of them genes directly associated to the yeast TORC1 pathway, underlie differences in ammonium and amino acids consumption under wine fermentation conditions [85] (Fig. 1). Also, allelic variants of RIM15 are involved in nitrogen source use variations [47] and utilization efficiency [41], with Rim15 being downstream TORC1. Thus, the experimental evidence obtained to date reinforces the suggested idea of the importance of this pleiotropic pathway (i.e. a pathway that contribute to the regulation of multiple developmental outcomes) in yeast adaptation to low nitrogen environments in wine fermentation [26]. It this sense, it is well stablished that signalling mechanisms that control development in yeast are highly pleiotropic, implying that perturbations of signalling pathways like TORC1 can manifest in multiple and/or unexpected ways [96].

\section{Wild yeast strains as reservoir of beneficial alleles}

Surprisingly, for four of the aforementioned TORC1related genes (NPR1, SAP185, SCH9 and TOR2), allelic variants from the wild NA strain (which correspond to an oak tree isolate [49]) presented higher consumption levels for certain amino acids (aspartic acid, histidine, glutamine and threonine) [85] (Fig. 1). Conversely, several studies have shown that alleles coming from the domesticated WE strain (which was isolated from a winemaking environment [49]) presented lower consumption levels for particular amino acids in comparison to other strains (NA, SA and WA) [41, 81, 83, 85].

These facts are quite interestingly, because one might thought that the WE strain would be better adapted to wine fermentation conditions that, for example, the NA strain, which is a wild isolate not adapted to this environment [49]. While this is true for ammonium consumption (a nitrogen source regularly in high proportion in grape must [36]), with alleles coming from WE strain causing higher rates of it [85], it is not for the consumption of certain amino acids (as abovementioned). It is still unclear if these amino acids are present in some natural environments (like oak bark) but absent in wine environments and if this is related to the specific demand for each amino acid, information that could help to better understand the differential nitrogen consumption between wine and wild yeast strains.

A possible explanation to this phenomenon is that, while wine yeast strains have been selected by humans for phenotypes directly linked to wine final characteristics (e.g. ethanol production and fermentation kinetics properties), wild yeast strains face environments with nitrogen limitations [47], being able to growth in a wider range of nitrogen sources than wine strains [48]. Therefore, these different evolutionary trajectories between wild and wine yeasts could have led to the existence of different genetic adaptations to nitrogen-limited environments, with wild strains better adapted to this condition, thus being a reservoir of beneficial alleles from an industrial point of view.

However, an alternative explanation is that wine yeasts have high nitrogen requirements because of the 


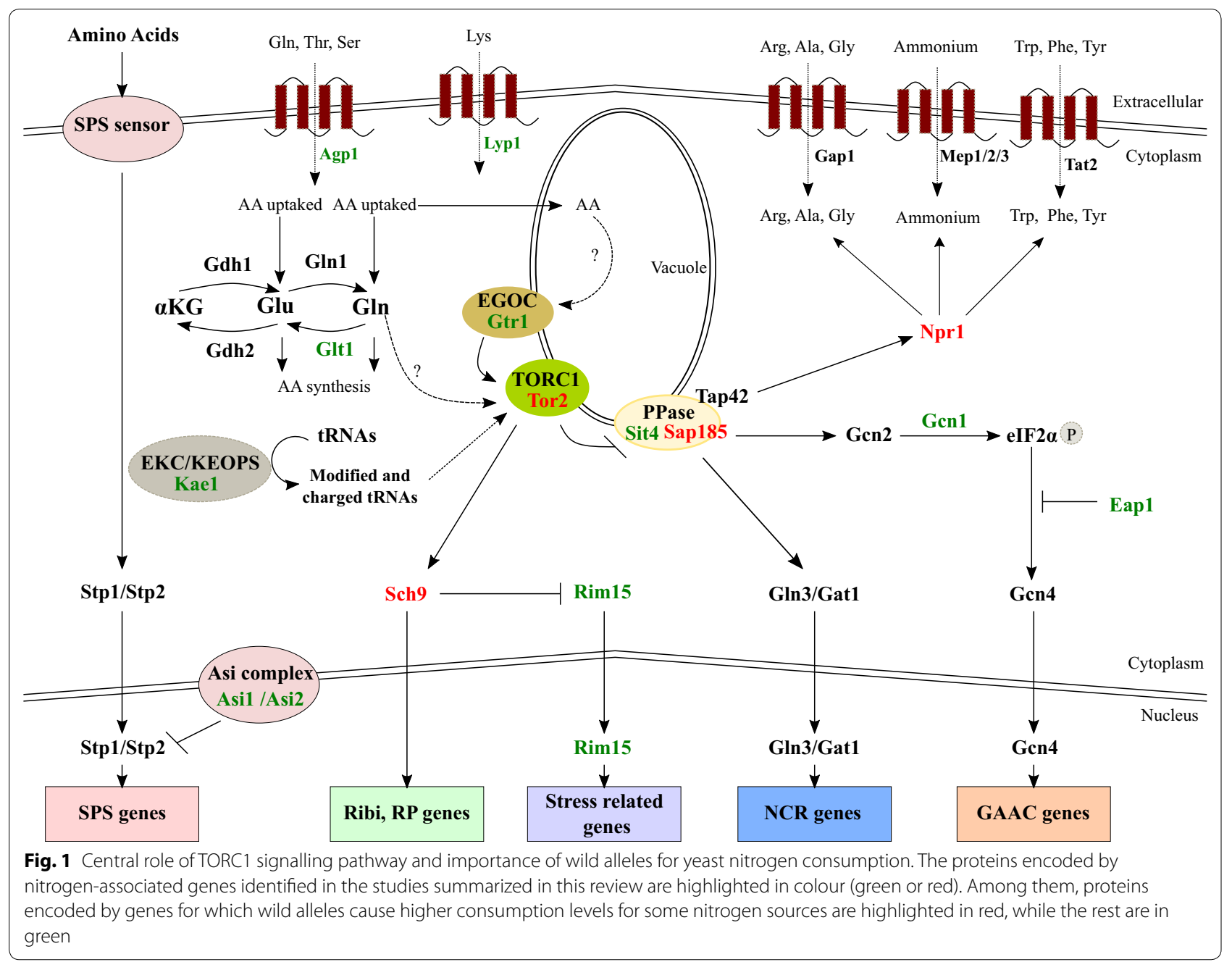

production of high concentrations of ethanol, while wild yeast only need the (low) nitrogen enough to allow growth and survival. Therefore, these differences could be a consequence of their metabolism related to the substrate where they develop rather than an environmental adaptation. New evidences towards one or another explanation are needed to gain a better understanding on this topic, like genomic and/or transcriptomic studies in nitrogen-limited fermentations comparing wine and wild yeast strains.

Even so, the hypothesis that wild yeast strains are better adapted to nitrogen-limited conditions is reinforced by the fact that alleles coming from WE strain tend to cause higher rates of ammonium consumption [85], which may be caused by the regular high proportion of this nitrogen source in the grape must [36] and the oenological practice of ammonium must supplementation [25]. All these antecedents are suggesting that wine yeasts are not well adapted to low nitrogen environments, requiring high levels of nitrogen to complete the fermentation process
[26]. Therefore, wild allelic variants augmenting amino acid consumption could be of industrial potential, e.g. for the improvement of industrial wine strains, maybe favouring amino acids consumption over ammonium, by genetic improvement programs.

\section{Future directions}

Although QTL mapping and "omics"-linked approaches have been the preferred tools for the identification of genes associated with yeast adaptation to low nitrogen fermentative conditions, another experimental strategy that can also be applied for phenotype-genotype correlations is Genome-wide association study (GWAS) [66]. This approach is based on a population of individuals without direct genetic relationship, which has been genotyped (generally by chips or sequencing) and phenotyped (for a specific trait), also allowing a direct correlation between genotype and phenotype [65]. While GWAS has been successfully applied in human populations for detection 
of risk genetic variants associated with diseases, when is applied to microorganism populations several confounding factors must be undertaken, such as selective sweeps, recombination frequency, horizontal gene transfer and clonal expansion [97].

In yeast, GWAS has been seldom utilized due to the necessity to genotype a large number of strains from diverse ecological niches, making the QTL mapping the preferred tool for the analysis of complex traits [65]. As far as we know, there is no study focused on nitrogen-related genes using GWAS. However, the recently sequenced "1011 yeasts population" overcome this problem, allowing to apply GWAS on this yeast population and becoming in a powerful resource for a direct association between genotype and phenotype [59]. Thus, we have now the chance to use GWAS as a tool for the identification of genes affecting phenotypes related to wine fermentation, particularly nitrogen utilization, as well as to TORC1 activation.

The GWAS experimental approach has also the advantage to allow the direct phenotypic and genotypic comparison between wild and domesticated yeast strains. S. cerevisiae is one of the most important domesticated species, due to its use for food (e.g. bread) and beverage (e.g. beer and wine) fermentations for thousands of years [98], but wild yeast strains also exist in non-human environments, such as tree barks and flowers [49]. However, little is known about the phenotypic effects linked to domestication in yeast, for example, over low nitrogen adaptation.

In this context, it will be of great importance for the yeast researcher community to study the effect that domestication process has had over these and other traits. Given the actual evidence pointing towards the different evolutionary trajectories of wild and domesticated yeast strains $[47,48,59,64]$, we can hypothesize that wild strains of $S$. cerevisiae are better adapted to low nitrogen conditions, being a reservoir of useful alleles to improve industrial yeasts for wine production. Moreover, this domestication process may have caused differences in TORC1 activation between wild and domesticated strains, with some works suggesting the existence of lineage-specific functional divergence for TORC1-associated phenotypes $[64,84,99,100]$, which in turn may have impacted on their fermentative capacities. The disentangling of the genetic bases of yeast adaptation to low nitrogen environments in wine fermentation will help to answer this and other questions, and to take the accumulated knowledge for industrial application in wine industry.

\section{Conclusions}

The study of the yeast natural diversity related to low nitrogen adaptation through QTL mapping and other experimental approaches (e.g. ASE) has helped to better understand the involvement of different genes (and alleles in specific) in phenotypes like growth kinetics, nitrogen sources consumption and fermentation kinetics. Moreover, several studies have left in evidence the central role of the TORC1 signalling pathway in nitrogen utilization and positioned wild yeast strains as a reservoir of useful alleles with potential industrial applications. More studies focused in disentangling the genetic bases of yeast adaptation to low nitrogen environments in wine fermentation will be of great importance to determine the phenotypic effects linked to domestication in yeast over low nitrogen adaptation, as well as to definitely proof that wild strains of $S$. cerevisiae are better adapted to low nitrogen conditions and use their beneficial alleles to improve industrial yeasts for wine production.

\begin{abstract}
Abbreviations
ASB: allele-specific transcription factor binding; ASE: allele specific expression; BSA: bulk segregant analysis; BSR-seq: bulk segregant RNA-seq; GWAS: Genome wide association study; ISA: individual segregant analysis; MHA: massive hemizygote analysis; QTL: quantitative trait locus; WYDC: wine yeast deletion collection.
\end{abstract}

\section{Acknowledgements}

Not applicable.

\section{Authors' contributions}

CM and EIKP designed the manuscript. EIKP wrote the manuscript with insights of all other authors. JM conceptualized and generated Fig. 1. All authors read and approved the final manuscript.

\section{Funding}

This work was supported by Universidad de Santiago de Chile [Grant USA1799-VRIDEI 081998SS-PAP] to EIKP and CONICYT/FONDECYT [Grant 1150522] to CM.

Availability of data and materials

Not applicable.

Ethics approval and consent to participate

Not applicable.

\section{Consent for publication}

Not applicable.

\section{Competing interests}

The authors declare that they have no competing interests.

\section{Author details}

${ }^{1}$ Departamento de Ciencia y Tecnología de los Alimentos, Universidad de Santiago de Chile (USACH), Santiago, Chile. ${ }^{2}$ Centro de Estudios en Ciencia y Tecnología de Alimentos (CECTA), Universidad de Santiago de Chile (USACH), Santiago, Chile.

Received: 12 November 2019 Accepted: 31 December 2019

Published online: 09 January 2020 


\section{References}

1. Goffeau A, Barrell BG, Bussey H, Davis RW, Dujon B, Feldmann H, et al. Life with 6000 genes. Science. 1996;274(5287):546, 563-7.

2. Gibson DG, Venter JC. Synthetic biology: construction of a yeast chromosome. Nature. 2014;509(7499):168-9.

3. Pretorius IS, Boeke JD. Yeast 2.0-connecting the dots in the construction of the world's first functional synthetic eukaryotic genome. FEMS Yeast Res. 2018;18(4):foy032.

4. Giaever G, Nislow C. The yeast deletion collection: a decade of functional genomics. Genetics. 2014;197(2):451-65.

5. Jensen MK, Keasling JD. Recent applications of synthetic biology tools for yeast metabolic engineering. FEMS Yeast Res. 2014;15(1):1-10.

6. Kim H, Yoo SJ, Kang HA. Yeast synthetic biology for the production of recombinant therapeutic proteins. FEMS Yeast Res. 2014;15(1):1-16.

7. Mokdad-Gargouri R, Abdelmoula-Soussi S, Hadiji-Abbes N, Amor IY, Borchani-Chabchoub I, Gargouri A. Yeasts as a tool for heterologous gene expression. Methods Mol Biol. 2012;824:359-70.

8. Bisson LF. The biotechnology of wine yeast. Food Biotechnol. 2007;18(1):63-96.

9. Borneman AR, Pretorius IS. Genomic insights into the Saccharomyces sensu stricto complex. Genetics. 2015;199(2):281-91.

10. Liti $\mathrm{G}$. The fascinating and secret wild life of the budding yeast S. cerevisiae. Elife. 2015;4:e05835.

11. Dequin S, Casaregola S. The genomes of fermentative Saccharomyces. C R Biol. 2011;334(8-9):687-93.

12. Querol A. Adaptive evolution of wine yeast. Int J Food Microbiol. 2003:86(1-2):3-10.

13. Garcia-Rios E, Guillamon JM. Mechanisms of yeast adaptation to wine fermentations. In: Sá-Correia I, editor. Yeasts in biotechnology and human health. Progress in molecular and subcellular biology. Cham: Springer; 2019. p. 37-59.

14. De Deken $\mathrm{RH}$. The Crabtree effect: a regulatory system in yeast. J Gen Microbiol. 1966:44(2):149-56.

15. Marsit S, Dequin S. Diversity and adaptive evolution of Saccharomyces wine yeast: a review. FEMS Yeast Res. 2015;15(7):fov067.

16. Goddard MR, Greig D. Saccharomyces cerevisiae: a nomadic yeast with no niche? FEMS Yeast Res. 2015;15(3):fov009.

17. Pfeiffer T, Morley A. An evolutionary perspective on the Crabtree effect. Front Mol Biosci. 2014;1:17.

18. Gobert A, Tourdot-Maréchal R, Sparrow C, Morge C, Alexandre H. Influence of nitrogen status in wine alcoholic fermentation. Food Microbiol. 2019;83:71-85.

19. Pretorius IS. Tailoring wine yeast for the new millennium: novel approaches to the ancient art of winemaking. Yeast. 2000;16(8):675-729.

20. Saito H, Posas F. Response to hyperosmotic stress. Genetics. 2012:192(2):289-318.

21. Bell SJ, Henschke PA. Implications of nitrogen nutrition for grapes, fermentation and wine. Aust J Grape Wine Res. 2005:11(3):242-95.

22. Varela C, Pizarro F, Agosin E. Biomass content governs fermentation rate in nitrogen-deficient wine musts. Appl Environ Microbiol. 2004;70(6):3392-400.

23. Bauer FF, Pretorius IS. Yeast stress response and fermentation efficiency: how to survive the making of wine-a review. S Afr J Enol Vitic. 2000;21(1):25.

24. Zuzuarregui A, Monteoliva L, Gil C, del Olmo M. Transcriptomic and proteomic approach for understanding the molecular basis of adaptation of Saccharomyces cerevisiae to wine fermentation. Appl Environ Microbiol. 2006;72(1):836-47.

25. Arias-Gil M, Garde-Cerdán T, Ancín-Azpilicueta C. Influence of addition of ammonium and different amino acid concentrations on nitrogen metabolism in spontaneous must fermentation. Food Chem. 2007;103(4):1312-8

26. Tesniere C, Brice C, Blondin B. Responses of Saccharomyces cerevisiae to nitrogen starvation in wine alcoholic fermentation. Appl Microbiol Biotechnol. 2015:99(17):7025-34

27. Broach JR. Nutritional control of growth and development in yeast. Genetics. 2012;192(1):73-105.

28. Zhang W, Du G, Zhou J, Chen J. Regulation of sensing, transportation, and catabolism of nitrogen sources in Saccharomyces cerevisiae. Microbiol Mol Biol Rev. 2018;82(1):e00040-17.
29. Conrad M, Schothorst J, Kankipati HN, Van Zeebroeck G, RubioTexeira M, Thevelein JM. Nutrient sensing and signaling in the yeast Saccharomyces cerevisiae. FEMS Microbiol Rev. 2014:38(2):254-99.

30. Ljungdahl PO, Daignan-Fornier B. Regulation of amino acid, nucleotide, and phosphate metabolism in Saccharomyces cerevisiae. Genetics. 2012;190(3):885-929.

31. Magasanik B, Kaiser CA. Nitrogen regulation in Saccharomyces cerevisiae. Gene. 2002;290(1-2):1-18.

32. Rodkaer SV, Faergeman NJ. Glucose- and nitrogen sensing and regulatory mechanisms in Saccharomyces cerevisiae. FEMS Yeast Res. 2014;14(5):683-96.

33. Hofman-Bang J. Nitrogen catabolite repression in Saccharomyces cerevisiae. Mol Biotechnol. 1999;12(1):35-73.

34. Cooper TG. Transmitting the signal of excess nitrogen in Saccharomyces cerevisiae from the Tor proteins to the GATA factors: connecting the dots. FEMS Microbiol Rev. 2002;26(3):223-38.

35. Mara P, Fragiadakis GS, Gkountromichos F, Alexandraki D. The pleiotropic effects of the glutamate dehydrogenase $(\mathrm{GDH})$ pathway in Saccharomyces cerevisiae. Microb Cell Fact. 2018;17(1):170.

36. ter Schure EG, van Riel NA, Verrips CT. The role of ammonia metabolism in nitrogen catabolite repression in Saccharomyces cerevisiae. FEMS Microbiol Rev. 2000;24(1):67-83.

37. Crepin L, Nidelet T, Sanchez I, Dequin S, Camarasa C. Sequential use of nitrogen compounds by Saccharomyces cerevisiae during wine fermentation: a model based on kinetic and regulation characteristics of nitrogen permeases. Appl Environ Microbiol. 2012;78(22):8102-11.

38. Brauer MJ, Huttenhower C, Airoldi EM, Rosenstein R, Matese JC, Gresham D, et al. Coordination of growth rate, cell cycle, stress response, and metabolic activity in yeast. Mol Biol Cell. 2008;19(1):352-67.

39. Brice C, Sanchez I, Tesniere C, Blondin B. Assessing the mechanisms responsible for differences between nitrogen requirements of Saccharomyces cerevisiae wine yeasts in alcoholic fermentation. Appl Environ Microbiol. 2014;80(4):1330-9.

40. Gutierrez A, Beltran G, Warringer J, Guillamon JM. Genetic basis of variations in nitrogen source utilization in four wine commercial yeast strains. PLOS ONE. 2013;8(6):e67166.

41. Jara M, Cubillos FA, Garcia V, Salinas F, Aguilera O, Liti G, et al. Mapping genetic variants underlying differences in the central nitrogen metabolism in fermenter yeasts. PLoS ONE. 2014:9(1):e86533.

42. Kessi-Perez El, Araos S, Garcia V, Salinas F, Abarca V, Larrondo LF, et al. RIM15 antagonistic pleiotropy is responsible for differences in fermentation and stress response kinetics in budding yeast. FEMS Yeast Res. 2016;16(3):fow021.

43. Gutierrez A, Chiva R, Sancho M, Beltran G, Arroyo-Lopez FN, Guillamon JM. Nitrogen requirements of commercial wine yeast strains during fermentation of a synthetic grape must. Food Microbiol. 2012;31(1):25-32.

44. Fay JC, Benavides JA. Evidence for domesticated and wild populations of Saccharomyces cerevisiae. PLoS Genet. 2005;1(1):66-71.

45. Martinez C, Cosgaya P, Vasquez C, Gac S, Ganga A. High degree of correlation between molecular polymorphism and geographic origin of wine yeast strains. J Appl Microbiol. 2007:103(6):2185-95.

46. Martinez C, Gac S, Lavin A, Ganga M. Genomic characterization of Saccharomyces cerevisiae strains isolated from wine-producing areas in South America. J Appl Microbiol. 2004;96(5):1161-8.

47. Legras JL, Merdinoglu D, Cornuet JM, Karst F. Bread, beer and wine: Saccharomyces cerevisiae diversity reflects human history. Mol Ecol. 2007;16(10):2091-102.

48. Ibstedt S, Stenberg S, Bages S, Gjuvsland AB, Salinas F, Kourtchenko $\mathrm{O}$, et al. Concerted evolution of life stage performances signals recent selection on yeast nitrogen use. Mol Biol Evol. 2015;32(1):153-61.

49. Liti G, Carter DM, Moses AM, Warringer J, Parts L, James SA, et al. Population genomics of domestic and wild yeasts. Nature. 2009:458(7236):337-41.

50. Schacherer J, Shapiro JA, Ruderfer DM, Kruglyak L. Comprehensive polymorphism survey elucidates population structure of Saccharomyces cerevisiae. Nature. 2009;458(7236):342-5.

51. Strope PK, Skelly DA, Kozmin SG, Mahadevan G, Stone EA, Magwene PM, et al. The 100-genomes strains, an S. cerevisiae resource that 
illuminates its natural phenotypic and genotypic variation and emergence as an opportunistic pathogen. Genome Res. 2015;25(5):762-74.

52. Legras JL, Galeote V, Bigey F, Camarasa C, Marsit S, Nidelet T, et al. Adaptation of S. cerevisiae to fermented food environments reveals remarkable genome plasticity and the footprints of domestication. Mol Biol Evol. 2018;35(7):1712-27.

53. Morales L, Dujon B. Evolutionary role of interspecies hybridization and genetic exchanges in yeasts. Microbiol Mol Biol Rev. 2012;76(4):721-39.

54. Novo M, Bigey F, Beyne E, Galeote V, Gavory F, Mallet S, et al. Eukaryoteto-eukaryote gene transfer events revealed by the genome sequence of the wine yeast Saccharomyces cerevisiae EC1118. Proc Natl Acad Sci USA. 2009;106(38):16333-8.

55. Gojkovic Z, Knecht W, Zameitat E, Warneboldt J, Coutelis JB, Pynyaha $Y$, et al. Horizontal gene transfer promoted evolution of the ability to propagate under anaerobic conditions in yeasts. Mol Genet Genomics. 2004;271(4):387-93.

56. Kominek J, Doering DT, Opulente DA, Shen XX, Zhou X, DeVirgilio J, et al. Eukaryotic acquisition of a bacterial operon. Cell. 2019;176(6):1356-1366.e10.

57. Hall C, Brachat S, Dietrich FS. Contribution of horizontal gene transfer to the evolution of Saccharomyces cerevisiae. Eukaryot Cell. 2005;4(6):1102-15.

58. Hall C, Dietrich FS. The reacquisition of biotin prototrophy in Saccharomyces cerevisiae involved horizontal gene transfer, gene duplication and gene clustering. Genetics. 2007;177(4):2293-307.

59. Peter J, De Chiara M, Friedrich A, Yue JX, Pflieger D, Bergstrom A, et al. Genome evolution across 1,011 Saccharomyces cerevisiae isolates. Nature. 2018;556(7701):339-44.

60. Wang QM, Liu WQ, Liti G, Wang SA, Bai FY. Surprisingly diverged populations of Saccharomyces cerevisiae in natural environments remote from human activity. Mol Ecol. 2012;21(22):5404-17.

61. Bergstrom A, Simpson JT, Salinas F, Barre B, Parts L, Zia A, et al. A high-definition view of functional genetic variation from natural yeast genomes. Mol Biol Evol. 2014;31(4):872-88.

62. Borneman AR, Desany BA, Riches D, Affourtit JP, Forgan AH, Pretorius IS, et al. Whole-genome comparison reveals novel genetic elements that characterize the genome of industrial strains of Saccharomyces cerevisiae. PLoS Genet. 2011;7(2):e1001287.

63. Ohya Y, Sese J, Yukawa M, Sano F, Nakatani Y, Saito TL, et al. High-dimensional and large-scale phenotyping of yeast mutants. Proc Natl Acad Sci USA. 2005;102(52):19015-20.

64. Warringer J, Zorgo E, Cubillos FA, Zia A, Gjuvsland A, Simpson JT, et al. Trait variation in yeast is defined by population history. PLoS Genet. 2011;7(6):e1002111.

65. Nieduszynski CA, Liti G. From sequence to function: insights from natural variation in budding yeasts. Biochim Biophys Acta. 2011;1810(10):959-66.

66. Liti G, Warringer J, Blomberg A. Budding yeast strains and genotypephenotype mapping. Cold Spring Harb Protoc. 2017;2017(8):pdb top077735.

67. Liti G, Warringer J, Blomberg A. Mapping quantitative trait loci in yeast. Cold Spring Harb Protoc. 2017;2017(8):pdb prot089060.

68. Mackay TF, Stone EA, Ayroles JF. The genetics of quantitative traits: challenges and prospects. Nat Rev Genet. 2009;10(8):565-77.

69. Cubillos FA, Parts L, Salinas F, Bergstrom A, Scovacricchi E, Zia A, et al. High-resolution mapping of complex traits with a four-parent advanced intercross yeast population. Genetics. 2013;195(3):1141-55.

70. Parts L, Cubillos FA, Warringer J, Jain K, Salinas F, Bumpstead SJ, et al. Revealing the genetic structure of a trait by sequencing a population under selection. Genome Res. 2011;21(7):1131-8.

71. Sinha H, Nicholson BP, Steinmetz LM, McCusker JH. Complex genetic interactions in a quantitative trait locus. PLoS Genet. 2006;2(2):e13.

72. Ehrenreich IM, Bloom J, Torabi N, Wang X, Jia Y, Kruglyak L. Genetic architecture of highly complex chemical resistance traits across four yeast strains. PLoS Genet. 2012;8(3):e1002570.

73. Torabi N, Kruglyak L. Genetic basis of hidden phenotypic variation revealed by increased translational readthrough in yeast. PLoS Genet. 2012;8(3):e1002546.

74. Lopez-Martinez G, Margalef-Catala M, Salinas F, Liti G, Cordero-Otero R. ATG18 and FAB1 are involved in dehydration stress tolerance in SaCcharomyces cerevisiae. PLoS ONE. 2015;10(3):e0119606.
75. Peltier E, Friedrich A, Schacherer J, Marullo P. Quantitative trait nucleotides impacting the technological performances of industrial Saccharomyces cerevisiae strains. Front Genet. 2019;10:683.

76. Ambroset C, Petit M, Brion C, Sanchez I, Delobel P, Guerin C, et al. Deciphering the molecular basis of wine yeast fermentation traits using a combined genetic and genomic approach. G3 (Bethesda). 2011;1(4):263-81.

77. Eder M, Sanchez I, Brice C, Camarasa C, Legras JL, Dequin S. QTL mapping of volatile compound production in Saccharomyces cerevisiae during alcoholic fermentation. BMC Genomics. 2018;19(1):166.

78. Salinas F, Cubillos FA, Soto D, Garcia V, Bergstrom A, Warringer J, et al. The genetic basis of natural variation in oenological traits in Saccharomyces cerevisiae. PLoS ONE. 2012;7(11):e49640.

79. Steyer D, Ambroset C, Brion C, Claudel P, Delobel P, Sanchez I, et al. QTL mapping of the production of wine aroma compounds by yeast. BMC Genomics. 2012;13:573.

80. Trindade de Carvalho B, Holt S, Souffriau B, Lopes Brandao R, FoulquieMoreno MR, Thevelein JM. Identification of novel alleles conferring superior production of rose flavor phenylethyl acetate using polygenic analysis in yeast. MBio. 2017;8(6):e01173-17.

81. Brice C, Cubillos FA, Dequin S, Camarasa C, Martinez C. Adaptability of the Saccharomyces cerevisiae yeasts to wine fermentation conditions relies on their strong ability to consume nitrogen. PLOS ONE. 2018;13(2):e0192383.

82. Brice C, Sanchez I, Bigey F, Legras JL, Blondin B. A genetic approach of wine yeast fermentation capacity in nitrogen-starvation reveals the key role of nitrogen signaling. BMC Genomics. 2014;15:495

83. Cubillos FA, Brice C, Molinet J, Tisne S, Abarca V, Tapia SM, et al. Identification of nitrogen consumption genetic variants in yeast through QTL mapping and bulk segregant RNA-Seq analyses. G3 (Bethesda). 2017;7(6):1693-705.

84. Kessi-Perez El, Salinas F, Gonzalez A, Su Y, Guillamon JM, Hall MN, et al. KAE1 allelic variants affect TORC1 activation and fermentation kinetics in Saccharomyces cerevisiae. Front Microbiol. 2019;10:1686.

85. Molinet J, Cubillos FA, Salinas F, Liti G, Martinez C. Genetic variants of TORC1 signaling pathway affect nitrogen consumption in Saccharomyces cerevisiae during alcoholic fermentation. PLOS ONE. 2019;14(7):e0220515.

86. Contreras A, Garcia V, Salinas F, Urzua U, Ganga MA, Martinez C. Identification of genes related to nitrogen uptake in wine strains of Saccharomyces cerevisiae. World J Microbiol Biotechnol. 2012;28(3):1107-13.

87. Barbosa C, Garcia-Martinez J, Perez-Ortin JE, Mendes-Ferreira A. Comparative transcriptomic analysis reveals similarities and dissimilarities in Saccharomyces cerevisiae wine strains response to nitrogen availability. PLOS ONE. 2015;10(4):e0122709.

88. Mendes-Ferreira A, del Olmo M, Garcia-Martinez J, Jimenez-Marti E, Mendes-Faia A, Perez-Ortin JE, et al. Transcriptional response of Saccharomyces cerevisiae to different nitrogen concentrations during alcoholic fermentation. Appl Environ Microbiol. 2007;73(9):3049-60.

89. Peter JJ, Watson TL, Walker ME, Gardner JM, Lang TA, Borneman A, et al. Use of a wine yeast deletion collection reveals genes that influence fermentation performance under low-nitrogen conditions. FEMS Yeast Res. 2018;18(3):foy009.

90. Salinas F, de Boer CG, Abarca V, Garcia V, Cuevas M, Araos S, et al. Natural variation in non-coding regions underlying phenotypic diversity in budding yeast. Sci Rep. 2016;6:21849.

91. Cubillos FA. Exploiting budding yeast natural variation for industrial processes. Curr Genet. 2016;62(4):745-51.

92. Cubillos FA, Billi E, Zorgo E, Parts L, Fargier P, Omholt S, et al. Assessing the complex architecture of polygenic traits in diverged yeast populations. Mol Ecol. 2011;20(7):1401-13.

93. Gonzalez A, Hall MN. Nutrient sensing and TOR signaling in yeast and mammals. EMBO J. 2017;36(4):397-408.

94. Kim J, Guan KL. Amino acid signaling in TOR activation. Annu Rev Biochem. 2011;80:1001-32.

95. Kessi-Perez El, Salinas F, Molinet J, Gonzalez A, Muniz S, Guillamon JM, et al. Indirect monitoring of TORC1 signalling pathway reveals molecular diversity among different yeast strains. Yeast. 2019;36(1):65-74.

96. Granek JA, Kayikci O, Magwene PM. Pleiotropic signaling pathways orchestrate yeast development. Curr Opin Microbiol. 2011;14(6):676-81. 
97. Power RA, Parkhill J, de Oliveira T. Microbial genome-wide association studies: lessons from human GWAS. Nat Rev Genet. 2017;18(1):41-50.

98. Gallone B, Mertens S, Gordon JL, Maere S, Verstrepen KJ, Steensels J. Origins, evolution, domestication and diversity of Saccharomyces beer yeasts. Curr Opin Biotechnol. 2018:49:148-55.

99. Li J, Vazquez-Garcia I, Persson K, Gonzalez A, Yue JX, Barre B, et al. Shared molecular targets confer resistance over short and long evolutionary timescales. Mol Biol Evol. 2019;36(4):691-708.
100. Vazquez-Garcia I, Salinas F, Li J, Fischer A, Barre B, Hallin J, et al. Clonal heterogeneity influences the fate of new adaptive mutations. Cell Rep. 2017;21(3):732-44.

\section{Publisher's Note}

Springer Nature remains neutral with regard to jurisdictional claims in published maps and institutional affiliations.
Ready to submit your research? Choose BMC and benefit from:

- fast, convenient online submission

- thorough peer review by experienced researchers in your field

- rapid publication on acceptance

- support for research data, including large and complex data types

- gold Open Access which fosters wider collaboration and increased citations

- maximum visibility for your research: over 100M website views per year

At BMC, research is always in progress.

Learn more biomedcentral.com/submissions 